Brit. J. industr. Med., 1955, 12, 87.

\title{
PRIMARY LUNG CANCER IN SOUTH WALES COAL-WORKERS WITH PNEUMOCONIOSIS
}

BY

\author{
W. R. L. JAMES \\ From the Department of Pathology and Bacteriology, Welsh National School of Medicine, Cardiff
}

(RECEIVED FOR PUBLICATION OCTOBER 28, 1954)

Coal-workers in the southern part of Wales are particularly prone to pulmonary disease due to the inhalation of coal dust. In some men discrete foci of dust are scattered more or less uniformly throughout both lungs. This is called simple pneumoconiosis. In others there occur also one or more large localized masses of dust and dense fibrous tissue (Fig. 1). This manifestation is referred to as massive pneumoconiosis or progressive massive fibrosis.

The literature contains many references to the coexistence of classical silicosis with primary lung cancer, but there are few accounts of coal-worker's pneumoconiosis with coexistent tumours. In a recent statistical study Kennaway and Kennaway (1953) have shown that primary cancer of the lung is less common in coal-workers than in the general male population. Their figures also show that in the South-Western Division of the British coalfields, where the incidence of pneumoconiosis is high, the incidence of lung tumour is low relative to that in other coalfields. In some other British coalfields where the pneumoconiosis incidence is low the tumour incidence is, for coal-workers, relatively high.

The object of the present inquiry was to obtain evidence regarding the relationship, if any, of pneumoconiosis to lung cancer in South Wales coal-workers.

The material was obtained during the six years 1947 to 1952 during which necropsies were made, in this department, on 1,827 coal-workers. During the same period post-mortem examinations were made of 1,531 South Wales males over the age of 21 not concerned with coal-mining. The pathological examinations of the miners were made on the instruction of coroners who had been told by the relatives that they considered death was due wholly or partly to dust disease. The symptoms of dust disease are well known to the mining community, and requests for necropsy are likely to be made by the relatives of men who have had chronic dyspnoea. This is shown by the high incidence of chronic lesions of the lung or cardiovascular system in this series. In many of the cases pneumoconiosis of varying degrees had been detected radiologically during life, and compensation had been paid.

It was considered that useful information might be obtained by studying the material as follows :

(1) Observation of the site of the cancer in relation to the site of the massive fibrosis in those in whom the two lesions coexisted ; (2) comparing the cancer cases in the miners and non-miners in respect of the histological types of the tumours, the spread of metastases, and the age distributions at death ; (3) by studying the incidence of cancer in relation to the severity of the dust lesion ; (4) by comparing the cancer incidence in the miners with that found at necropsy in non-miners.

At necropsy one of each pair of lungs was distended by formol-sodium-acetate solution with a view to the preparation of a large section by the technique of Gough and Wentworth (1949). The other lung was cut at the time of the necropsy and after naked-eye examination pieces were excised for microscopic study.

\section{Results}

Of the 1,827 miners, 967 had simple pneumoconiosis and 860 had massive fibrosis. Primary lung cancer was found in $49(5.1 \%)$ of those with simple pneumoconiosis and in $12(1.4 \%)$ of those having massive disease. Of the 12 with primary lung cancer and coexisting massive fibrosis, the tumour was in the lesion, or touching it in five cases (Fig. 1), and it was remote from the lesion in the other seven. If coal dust has a local carcinogenic effect it would be likely to lead to cancer in that part of the lung in which the dust concentration is greatest, which is at the site of massive fibrosis. 


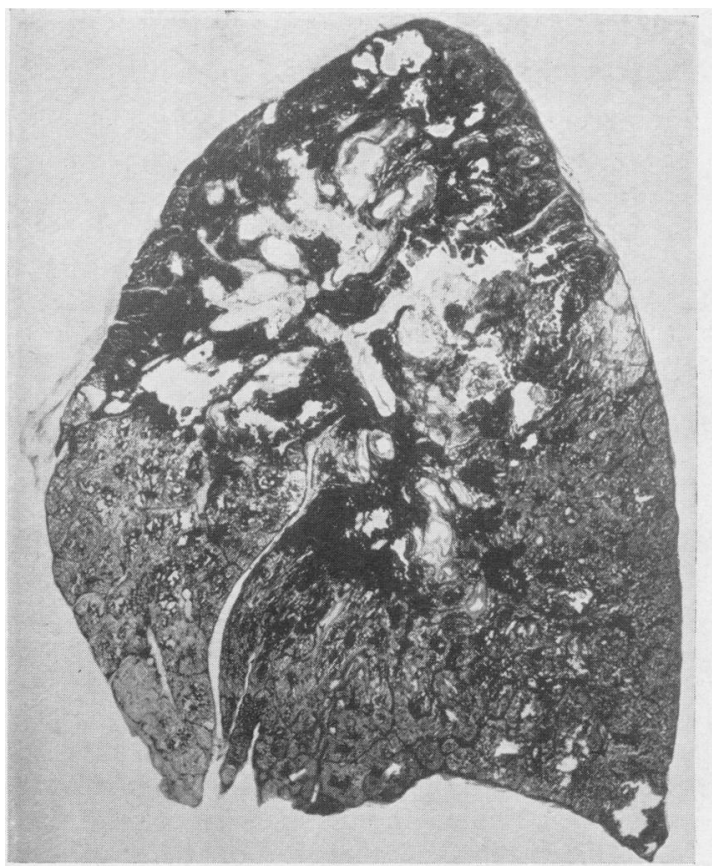

Fig. 1.-This section of the right lung of a coal-worker of 64 shows a tumour surrounded by massive dust fibrosis. The symptoms were similar to those of pneumoconiosis alone.

In those with massive fibrosis and cancer one would therefore expect to find a preponderance of the tumours in or near the dust lesion. The fact that seven of the 12 cancers were remote from dust lesions suggests that it is unlikely that the dust has a local carcinogenic effect.

Material from the lung tumours was available for microscopic examination in 56 of the lesions from miners and in 77 of the tumours found in non-miners. It was considered that if lung cancer in miners had a different aetiology from that in nonminers the difference might be shown in the microscopic structure. The lesions were therefore classified according to the methods adopted by Mulligan (1951) and Willis (1952) with the results shown in Table 1.

It is apparent from Table 1 that there is a general similarity in the distribution of the various histological types in miners and non-miners, and that if coal has any aetiological effect it is not suggested by any difference in the histological appearance.

Fifty-seven of the 61 miners with lung cancer had died from it. The distribution of metastases in the 57 was compared with that in the 82 non-miners who had died of lung cancer. Table 2 shows the number of metastases found at 12 sites in each group, with the percentage incidence. The figures
TABLE 1

HISTOLOGICAL TYPES OF 77 LUNG CANCERS IN NONMINERS AND 56 LUNG CANCERS IN COAL-MINERS

\begin{tabular}{|c|c|c|c|c|}
\hline \multicolumn{3}{|c|}{ Histological Type } & Non-miners & Miners \\
\hline $\begin{array}{l}\text { Anaplastic only } \\
\text { Squamous only } \\
\text { Adenocarcinoma } \\
\text { Others, including }\end{array}$ & $\begin{array}{ll}\because & \because \\
\text { only } & \because \\
\text { mixed } \\
\text { types }\end{array}$ & $\begin{array}{l}\ldots \\
\because \\
\cdots\end{array}$ & $\begin{array}{rr}39 & (50 \cdot 6 \%) \\
32 & (41 \cdot 6 \%) \\
5 & (6 \cdot 5 \%) \\
1 & (1.3 \%)\end{array}$ & $\begin{aligned} 29 & (52 \%) \\
23 & (41 \%) \\
2 & (3.5 \%) \\
2 & (3.5 \%)\end{aligned}$ \\
\hline Totals & .. & .. & $77(100 \%)$ & $56(100 \%)$ \\
\hline
\end{tabular}

show that there is a general similarity in the frequencies with which metastases are found at these sites. The greatest difference observed was in respect of the brain, where secondary lesions occurred in $27 \%$ of the non-miners but in only $9 \%$ of the miners.

TABLE 2

FREOUENCY OF METASTASES AT CERTAIN SITES IN 57 MINERS AND 82 NON-MINERS DYING FROM PRIMARY LUNG CANCER

\begin{tabular}{|c|c|c|c|c|}
\hline Site & & & Non-miners & Miners \\
\hline $\begin{array}{l}\text { Lymph glands } \\
\text { Adrenals } \\
\text { Liver .. } \\
\text { Brain .. } \\
\text { Skeleton .. } \\
\text { Pericardium } \\
\text { Kidneys } \\
\text { Pancreas .. } \\
\text { Myocardium } \\
\text { Thyroid .. } \\
\text { Peritoneum } \\
\text { Others .. }\end{array}$ & $\begin{array}{l}\ldots \\
\cdots \\
\cdots \\
\cdots \\
\cdots \\
\therefore \\
\therefore \\
\cdots\end{array}$ & $\begin{array}{l}\cdots \\
\cdots \\
\cdots \\
\cdots \\
\cdots \\
\cdots \\
\cdots \\
\cdots\end{array}$ & $\begin{array}{c}76(93 \%) \\
29(35 \%) \\
25(31 \%) \\
22(27 \%) \\
17(21 \%) \\
8(10 \%) \\
6(7 \cdot 3 \%) \\
4(4.9 \%) \\
3(3.7 \%) \\
2(2 \cdot 5 \%) \\
1(1.2 \%) \\
14(17 \%)\end{array}$ & $\begin{array}{c}50(88 \%) \\
11(19 \%) \\
21(37 \%) \\
5(9 \%) \\
6(10 \%) \\
4(7 \%) \\
7(12 \%) \\
3(5 \%) \\
3(5 \%) \\
2(3.5 \%) \\
2(3.5 \%) \\
8(14 \%)\end{array}$ \\
\hline
\end{tabular}

Table 3 shows data relevant to the comparative frequency of death in each age group in the miners and non-miners. The figures show that the miners resemble the non-miners in that there was in both a preponderance of lung cancer in the age groups 50 to 69 years.

Whole lung sections were use to classify the 967 cases of simple pneumoconiosis into three groups showing respectively slight, moderate, and severe degrees of the condition. The classification was made by comparing each lung section with two standard sections. One of the latter was designated as the upper limit of slight simple pneumoconiosis, the other was chosen to represent the lower limit of severe simple pneumoconiosis. Table 4 shows the distribution of the cancer cases in the miners in relation to the various degrees of pneumoconiosis, and in relation to the incidence in non-miners.

Thus, taking the average incidence for all miners as 100 , the incidence in miners with slight simple pneumoconiosis is 177 which approximately equals that in the group of non-mining males. The relative incidence diminishes with increasing severity of the pneumoconiosis and is least in those with massive fibrosis. It is necessary to consider whether this observed relative deficiency of cancer in miners with 
TABLE 3

COMPARATIVE FREQUENCY OF DEATH RELATED TO AGE IN MINERS AND NON-MINERS

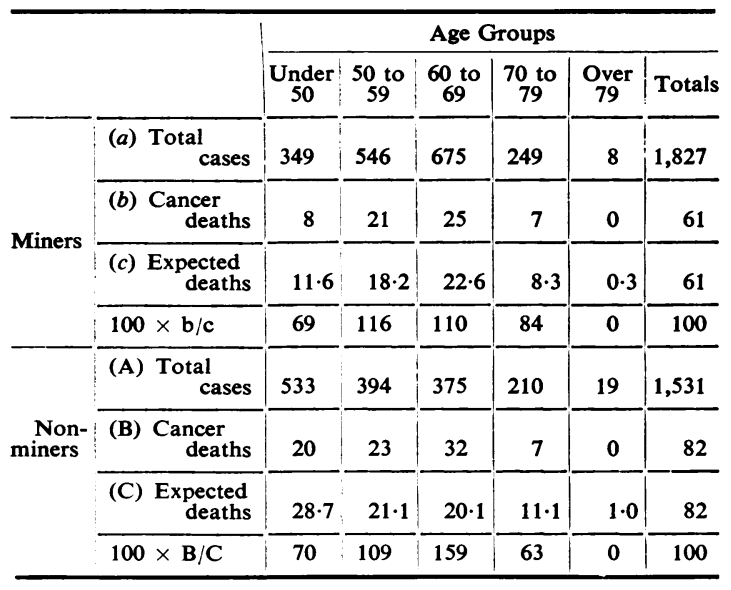

TABLE 4

DISTRIBUTION OF LUNG CANCER IN 1,827 SOUTH WALES MINERS WITH VARIOUS DEGREES OF PNEUMOCONIOSIS COMPARED WITH THE INCIDENCE IN 1,531 SOUTH WALES NON-MINERS OVER THE AGE OF 21

\begin{tabular}{l|c|c|c|c|c|c}
\hline & \multicolumn{2}{|c|}{$\begin{array}{c}\text { Simple } \\
\text { Pneumoconiosis }\end{array}$} & $\begin{array}{c}\text { Massive } \\
\text { Pneumo- } \\
\text { coniosis }\end{array}$ & $\begin{array}{c}\text { All } \\
\text { Miners }\end{array}$ & $\begin{array}{c}\text { All } \\
\text { Non- } \\
\text { miners }\end{array}$ \\
\hline (a) Total cases & 524 & 272 & 171 & 860 & 1,827 & 1,531 \\
\hline $\begin{array}{l}\text { (b) Cancer cases } \\
\text { Slight }\end{array}$ & 31 & 11 & 7 & 12 & 61 & 82 \\
\hline $\begin{array}{c}\text { (c) Cancers ex- } \\
\text { pected on } \\
\text { the basis of } \\
\text { all miners' } \\
\text { necropsies. }\end{array}$ & $17 \cdot 5$ & $9 \cdot 1$ & $5 \cdot 7$ & $28 \cdot 7$ & 61 & $51 \cdot 0$ \\
\hline $100 \times$ b/c $\ldots$ & 177 & 121 & 122 & 42 & 100 & 161 \\
\hline
\end{tabular}

severe pneumoconiosis is true only in respect of the present series, and whether it is a result of the way in which the material was obtained. It seems possible that the method of selection resulted in the exclusion of some cases of massive fibrosis with cancer. Such exclusion is, however, unlikely since compensation is payable to the dependants if death is in any way related to massive pneumoconiosis, even if cancer coexists. Moreover, the diagnosis of cancer in those with simple pneumoconiosis is relatively easy, and in those with massive pneumoconiosis the diagnosis of coexisting cancer is radiologically difficult or impossible. Thus of the 12 with massive fibrosis and cancer, the latter was diagnosed before necropsy in only two (Figs. 2, 3, 4). Hence if cases were excluded because of clinically diagnosed cancer one would expect those with tumour and simple pneumoconiosis to be excluded, rather than those with tumour and massive fibrosis. The similarity of the cancer incidence in those with slight simple pneumoconiosis to the incidence in non-miners suggests that the diagnosis of cancer before necropsy has not been a factor in excluding miners from the present series. It would seem that in most of those cases in which cancer had been diagnosed, and in which it had even been accepted as the main cause of death, the relatives considered that dust disease might have been a contributory factor in causing death, and that a necropsy should be done.

It seemed possible that early death from pneumoconiosis might be a factor reducing the incidence of lung cancer in miners. In this connexion, of the 1,827 coal-workers studied, 469 died from dust disease alone. Of the 469 , none died under the age of $30,88(18 \cdot 7 \%)$ died under the age of 50 , and only $59(12.5 \%)$ reached the age of 70 . Data published by the Registrar-General from 1949 to 1953 (average for the years 1947 to 1951) show that of males in the general population who reached the age of 30 , only $9.8 \%$ died under 50 , and $50.6 \%$ survived over the age of 70. Of all miners dying of dust disease it is possible that some selection takes place on an age basis and that relatively fewer of the older men are examined after death. My own experience suggests that if such selection occurs at all, the number of old men so excluded is so small that it does not disturb the general conclusion that pneumoconiosis carries a risk of death at a relatively early age. It is therefore possible that relatively early death from pneumoconiosis has the effect of reducing the incidence of lung cancer in miners in a coalfield such as South Wales where pneumoconiosis causes many deaths.

The incidence of primary lung cancer found by various authors at necropsy is summarized below.

Gooding (1946) in South Wales coal-workers .. $\quad \ldots \quad \ldots \quad 0.8 \%$

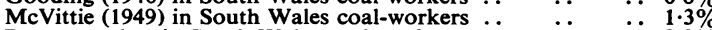
Present author in South Wales coal-workers . $\quad \ldots \quad$. $3.3 \%$

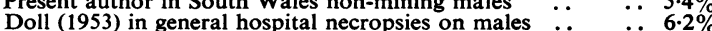

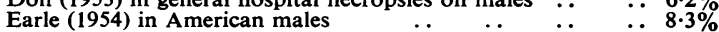

Data derived from necropsy studies have the merit of accuracy of diagnosis but the disadvantage of inevitable difficulties in controlling the sample. It can, however, be said that the different incidences reported do not suggest that inhaled coal dust is carcinogenic.

\section{Discussion}

The relationship of classical silicosis to lung cancer has been studied by many authors, with divergent results. Dible (1934), Klotz (1939), and Anderson and Dible (1938) obtained pathological evidence suggesting that silicosis predisposes to lung tumour. Data suggesting that there was no 


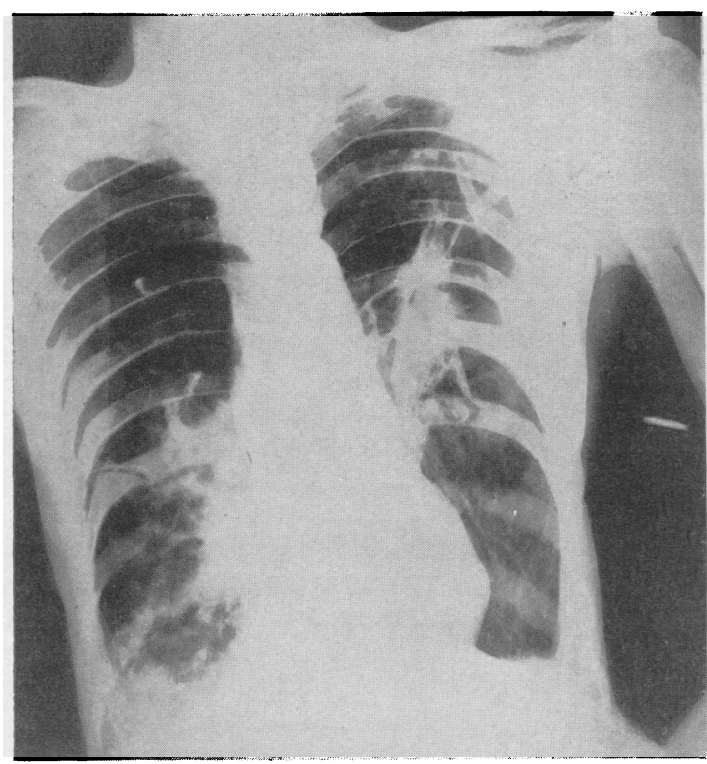

Fig. 2.-The opacity in the left lung was due to massive pneumoconiosis. The opacity in the right lower lobe was due to massive pneumoconiosis and cancer.

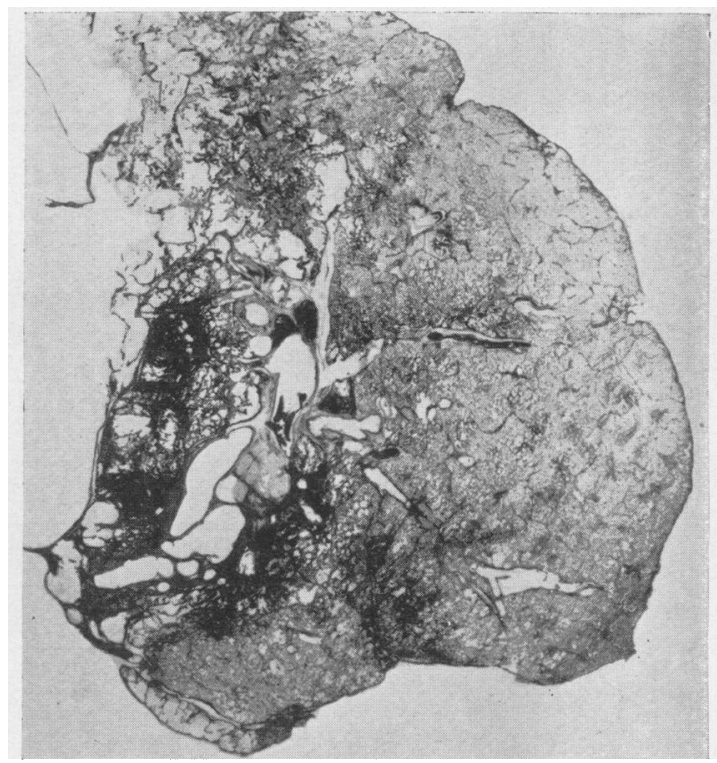

FIG. 3.-A section of the right lung of a miner aged 71, showing massive pneumoconiosis and cancer near the hilum. The radiograph (Fig. 2) was considered to be suggestive but not diagnostic of cancer.

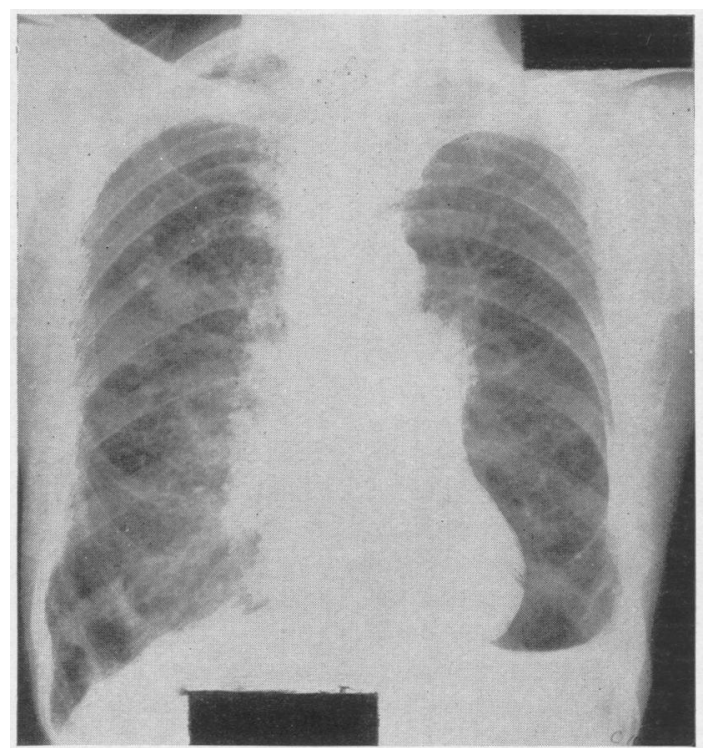

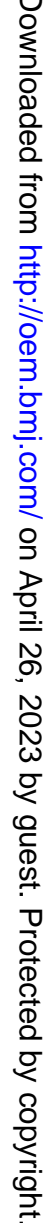

Fig. 4.-This radiograph of a coal-worker of 69 was taken 14 months before death. The lung fields show simple pneumoconiosis and a small area of massive fibrosis. The opacity in the left hilar region was considered to be due to enlargement of the hilar glands and pulmonary conus, due to dust disease. At necropsy there was a $10 \mathrm{~cm}$. tumour at the left hilum. 
aetiological relationship were published by Sladden (1933), Sweany, Porsche, and Douglass (1936), Vorwald and Karr (1938), the Chief Inspector of Factories (1939), Smith (1947), and Schoch (1954).

In the 30th Annual Report of the British Empire Cancer Campaign (1953) the comment is made that there is very little information about the importance, if any, of coal mining as a cause of lung cancer. Information of some relevance to the present study was published by Raeburn and Spencer (1953), who found that 11 out of 15 small lung cancers were near lung scars. The lung of the coal-worker, like his skin, frequently shows many dust-laden scars, and the infrequency of small tumours of the lung and skin in relationship to the frequent scars suggests that the coal-dust is not carcinogenic.

Stocks (1952), in an epidemiological study, observed that the comparative mortality rates from lung cancer in Merthyr Tydfil, Cardiff, and Swansea were respectively 77,126 , and 132 . A large proportion of the population of Merthyr Tydfil is engaged in coal mining, whereas few coal-workers reside in Cardiff or Swansea. The total population of each of the latter is greater than that of Merthyr Tydfil, but even when allowance has been made for the known higher cancer incidence due to increased urbanization it appears that there is a relative preponderance of the tumour in the two non-mining populations.

In 1954 Blacklock, Kennaway, Lewis, and Urquhart reported on their study of the carbon content of the lungs in subjects who were not selected on an occupational basis. Part of their investigation involved the determination of the carbon content of the lungs of 26 London males, 16 of whom had lung cancer. In the cancer group the average total carbon content was $0.75 \mathrm{~g}$. In the 10 without lung tumour the average carbon content was higher $(0.9 \mathrm{~g}$.). A similar study of the lungs of females showed that the total carbon was higher in the cancer group than in those without cancer.

The present study shows that lung cancer is found at necropsy less frequently in coal-miners than in male non-miners of the same age group. It is possible that this discrepancy may be partly due to factors in the selection of the material. It seems likely, however, that the manner in which the material was obtained would tend to increase the observed incidence of lung tumours at necropsy in the miners, since the cases are selected mainly on the basis of a history of chronic lung disease.
The fatal cases of pneumoconiosis in this series show that in such cases there is a substantial reduction in the span of adult life and therefore less risk of lung cancer. The observed relatively low incidence of the tumour may be partly due to the effect of dust disease on survival.

\section{Summary}

Primary lung cancer was found at necropsy in $3.3 \%$ of 1,827 South Wales coal-miners and in $5.4 \%$ of 1,531 South Wales non-miners.

In 12 cases of lung cancer with massive pneumoconiosis the tumour was in the mass, or touching it, in five. In the other seven the tumour was remote.

Lung cancer in South Wales miners is similar to that in non-miners in respect of the ages at death, the distribution of the histological variants of the tumour, and the distribution of metastases.

The significance of these findings is discussed. Attention is drawn to the difficulty of diagnosing lung cancer in the presence of massive pneumoconiosis.

The author acknowledges with gratitude the help of Professor Gough who provided the material and made many helpful suggestions. Dr. A. G. Heppleston assisted with useful criticism. Dr. Lewis Faning was very helpful in giving general advice regarding the statistical procedures. The photographs and lung sections were prepared by Mr. J. P. Napper and Mr. J. E. Wentworth respectively.

\section{REFERENCES}

Anderson, C. S., and Dible, J. H. (1938). J. Hyg., Camb., 38, 185. Blacklock, J. W. S., Kennaway, E. L., Lewis, G. M., and Urquhart, M. E. (1954). Brit. J. Cancer, VIII, 40.

British Enpire Cancer Campaign (1953). 30th Annual Report, 1952 , p. 109.

Chief Inspector of Factories (1939). Annual Report for 1938, p. 81. Dible, J. H. (1934). Lancet, 2, 982.

Earle, K. M. (1954). Arch. Path., Chicago, 57, 106

Gooding, C. G. (1946). Lancet, 2, 891.

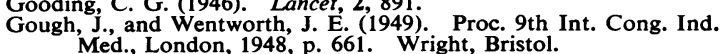

Kennaway, E. L., and Kennaway, N. M. (1953). Brit. J. Cancer,

Klotz, M. O. (1939). Amer. J. Cancer, 35, 38.

McVittie, J. C. (1949). Postgrad. med. J., 25, 618.

Mulligan, R. M. (1951). Syllabus of Human neoplasma, p. 149. Henry Kimpton, London.

Raeburn, G., and Spencer, H. (1953). Thorax, 8, 1.

Registrar-General (1949-53). Statistical Reviews of England and Wales for 1947 to 1951 inclusive.

Schoch, Hans, (1954). Z. Unfallmed. Berufskr., 47, 138 and 184.

Sladden, A. F. (1933). Lancet, 2, 123.

Smith, J. M. (1947). In Silicosis, Pneumokoniosis and Dust Suppression in Mines. Proc. Joint Conference of Inst. Min. Eng. and Inst. Min. Metall., p. 88. London.

Stocks, P. (1952). Brit. J. Cancer, VI, 99.

Sweany, H. C., Porsche, J. D., and Douglass, J. R. (1936). Arch. Path., Chicago, 22, 593.

Vorwald, A. J., and Karr, J. W. (1938). Amer. J. Path., 14, 49.

Willis, R. A. (1952). The Spread of Tumours in the Human Body, 2nd ed., p. 314. Butterworth, London. 